\title{
RNA Interference of Effector Gene Mc16D10L Confers Resistance Against Meloidogyne chitwoodi in Arabidopsis and Potato
}

\author{
Phuong T. Y. Dinh, Charles R. Brown, and Axel A. Elling
}

First and third authors: Department of Plant Pathology, Washington State University, Pullman 99164; and second author: Vegetable and Forage Crops Research Unit, U.S. Department of Agriculture-Agricultural Research Service, Prosser, WA 99350. Accepted for publication 9 April 2014.

\section{ABSTRACT}

Dinh, P. T. Y., Brown, C. R., and Elling, A. A. 2014. RNA interference of effector gene Mc16D10L confers resistance against Meloidogyne chitwoodi in Arabidopsis and potato. Phytopathology 104:1098-1106.

Meloidogyne chitwoodi, a quarantine pathogen, is a significant problem in potato-producing areas worldwide. In spite of considerable genetic diversity in wild potato species, no commercial potato cultivars with resistance to $M$. chitwoodi are available. Nematode effector genes are essential for the molecular interactions between root-knot nematodes and their hosts. Stable transgenic lines of Arabidopsis and potato (Solanum tuberosum) with resistance against $M$. chitwoodi were developed. RNA interference (RNAi) construct pART27(16D10i-2) was introduced into Arabidopsis thaliana and potato to express double- stranded RNA complementary to the putative $M$. chitwoodi effector gene Mc16D10L. Plant-mediated RNAi led to a significant level of resistance against M. chitwoodi in Arabidopsis and potato. In transgenic Arabidopsis lines, the number of $M$. chitwoodi egg masses and eggs was reduced by up to 57 and $67 \%$ compared with empty vector controls, respectively. Similarly, in stable transgenic lines of potato, the number of $M$. chitwoodi egg masses and eggs was reduced by up to 71 and $63 \%$ compared with empty vector controls, respectively. The relative transcript level of Mc16D10L was reduced by up to $76 \%$ in M. chitwoodi eggs and infective second-stage juveniles that developed on transgenic pART27(16D10i-2) potato, suggesting that the RNAi effect is systemic and heritable in $M$. chitwoodi.
Potato (Solanum tuberosum L.) is the most important noncereal food crop worldwide and makes up the staple diet of over 1 billion people $(4,28)$. Plant-parasitic nematodes are a major threat to potato production worldwide, with root-knot (Meloidogyne spp.) and cyst nematodes (Globodera spp.) being the most widespread and causing most of the damage (6). In the Pacific Northwest of the United States, which is the leading potato growing area and accounts for more than half of the country's total production (2), the Columbia root-knot nematode (Meloidogyne chitwoodi Golden et al.) is the most common and significant nematode threat to sustainable potato cultivation. $M$. chitwoodi is not only a problem in the United States but has also been found in potato growing regions in Europe, Mexico, Argentina, and South Africa, making it a threat in some of the world's most important potato production areas (21). M. chitwoodi causes tuber quality defects and can render entire shipments unmarketable (24). It has been estimated that as little as one juvenile per $250 \mathrm{~g}$ of soil at the beginning of the growing season can lead to a total loss of marketability at harvest (42). To limit spread, M. chitwoodi has been designated as a quarantine pest, which has a significant impact on the international trade of potato tubers (1).

Meloidogyne spp. are obligate parasites that depend on their host plant for survival. The pathogenic part of the life cycle of root-knot nematodes begins with the second-stage juveniles (J2), which are the infective life stage and invade plant roots, rhizomes, and tubers. The $\mathrm{J} 2$ migrate intercellularly through host tissue until

Corresponding author: A. A. Elling; E-mail address: elling@wsu.edu

* The $\boldsymbol{e}$-Xtra logo stands for "electronic extra" and indicates that the online version contains one supplemental figure. Figures 1 and 2 appear in color online.

http://dx.doi.org/10.1094/PHYTO-03-14-0063-R

This article is in the public domain and not copyrightable. It may be freely reprinted with customary crediting of the source. The American Phytopathological Society, 2014 they become sedentary and induce the formation of giant cells, which constitute the nematodes' feeding sites and sole source of nutrition. The exact mechanisms that lead to the formation and maintenance of giant cells are unknown, but generally it is thought that secretory proteins from the nematode esophageal gland cells, i.e., effectors, play a key role in the underlying processes (54). After a feeding site has been established, the J2 increase in size and undergo subsequent molts into third- and fourth-stage juveniles (J3 and J4). After a final molt they develop into adult females or males. Adult females deposit eggs into egg masses, a gelatinous matrix that protects eggs from desiccation. Inside the eggs, first-stage juveniles (J1) develop and molt into J2, which hatch under favorable conditions that are mostly dictated by soil moisture and temperature (58). Nematode control in most potato growing areas is based on routine applications of synthetic nematicides. This practice not only is costly but also potentially harmful to the environment because some products have been linked to negative effects on the atmosphere's ozone layer (60). Host resistance against root-knot nematodes would be an ideal control strategy, but is difficult to achieve.

In spite of the extremely rich genetic resources found in Solanum sect. Petota, which consists of wild and cultivated potatoes and includes up to 232 tuber-bearing and non-tuber-bearing species $(25,27,64,65)$, exploiting this genetic diversity and introducing $M$. chitwoodi resistance into cultivated potato (S. tuberosum sp. tuberosum) has proven to be challenging. Germplasm evaluation identified resistance against $M$. chitwoodi in a number of potato species, including $S$. brachistrotrichum (Bitter) Rydb., S. bulbocastanum Dunal, S. cardiophyllum Lindl., S. chacoense Bitter, S. fendleri Gray, S. hougasii Corr., and S. stoloniferum Schltdl. (7,9,10,44-46). Protoplast fusions and sexual hybridization were used to introgress $M$. chitwoodi resistance from $S$. bulbocastanum, S. fendleri, S. hougasii, and $S$. stoloniferum into cultivated potato $(8,11,12,47)$ but recent analyses indicate that the same single dominant monogene, $R_{M c l}$, 
might be responsible for the resistance found in $S$. bulbocastanum, S. fendleri, and S. hougasii (15). In spite of over two decades of breeding efforts no commercial potato cultivar with resistance to $M$. chitwoodi is available to date. The $R_{M c l(b l b)}$ gene from $S$. bulbocastanum has been used to develop advanced $S$. tuberosum breeding clones, but $M$. chitwoodi populations are very variable $(34,35)$ and some isolates are able to overcome the $R_{M c l(b l b)}$ gene, presenting a significant problem for traditional resistance breeding $(13,48)$. Furthermore, hairy nightshade ( $S$. sarrachoides Sendtn.), a common weed in potato producing areas in the western United States and a host for M. chitwoodi, was found to undermine resistance under greenhouse and field conditions when it co-occurs with potato breeding lines carrying the $R_{M c l(b l b)}$ resistance gene (5).

Given these challenges, transgenic approaches, and in particular the use of RNA interference (RNAi), could be an attractive alternative for nematode control. Plant-parasitic nematodes are known to take up host cytoplasm during the infection process, making them vulnerable to host-derived compounds, including double-stranded RNA (dsRNA) and small interfering RNA (siRNA). This dependency has been exploited recently by engineering transgenic plant tissue that overexpresses dsRNA that is complementary to nematode genes (for recent reviews see 22, 49,51). However, plant-mediated RNAi technology to create nematode resistance has been restricted largely to the model plant Arabidopsis thaliana and Agrobacterium rhizogenes-induced transgenic hairy roots $(31,40,63,71)$. Stable transformation of agriculturally important crops to implement host-mediated RNAi against nematodes has been achieved only in tobacco (Nicotiana tabacum L.) and soybean (Glycine max (L.) Merr.) to date, and with greatly varying levels of resistance $(23,66,72)$. In some of these cases, nematode genes were targeted that are conserved in other animals, and could prove problematic when implemented in the field. Targeting genes that are specific to plant-parasitic nematodes to eliminate off-target effects might provide a better option if this technology is to be employed in crops. The effector gene $16 D 10$ has shown great promise as an RNAi target in other Meloidogyne spp. (31), but it is unknown whether this gene exists in $M$. chitwoodi and whether it can be used to create stable resistance against this nematode, especially in agronomically important crops. Therefore, the objective of this study was to test whether creating stable transgenic lines of Arabidopsis and potato that overexpress dsRNA complementary to the Meloidogynespecific effector gene $16 D 10$ leads to resistance against M. chitwoodi.

\section{MATERIALS AND METHODS}

Nematode maintenance and extraction. $M$. chitwoodi isolate WAMC1 was maintained on tomato (S. lycopersicum L.) 'Rutgers' under greenhouse conditions (34). Tomato plants were grown in autoclaved sand. Three months after inoculation, M. chitwoodi eggs and parasitic life stages were harvested from tomato roots. To extract eggs, roots were cut into small pieces and agitated for $3 \mathrm{~min}$ in a $0.5 \%$ sodium hypochlorite solution (36). The root suspension was poured over a set of nested test sieves $(850,75$, and $25 \mu \mathrm{m}$ pore size from top to bottom) and eggs were collected from the $25-\mu \mathrm{m}$ sieve. To purify samples, the $M$. chitwoodi egg suspension was divided into $50-\mathrm{ml}$ tubes $(20 \mathrm{ml}$ per tube) and mixed with $20 \mathrm{ml}$ of $70 \%$ sucrose. Ten milliliters of water was carefully placed on top of the suspension and the tubes were immediately centrifuged for $3 \mathrm{~min}$ at $375 \times g$ in a clinical centrifuge. After centrifuging, eggs were collected from the interface and rinsed on a $25-\mu \mathrm{m}$ test sieve. To hatch infective $\mathrm{J} 2$, purified eggs were incubated in a modified Baermann pan with sterile water at room temperature for 4 days; hatched infective $\mathrm{J} 2$ were collected by centrifugation (19). To extract parasitic nematode life stages, root pieces from which eggs were extracted were blended in tap water and decanted over a set of four nested test sieves (250, 125, 45, and $25 \mu \mathrm{m}$ pore size from top to bottom). Each sieve was rinsed for 2 min with tap water. M. chitwoodi females were collected from the $125-\mu \mathrm{m}$ sieve, parasitic $\mathrm{J} 3$ and $\mathrm{J} 4$ from the $45-\mu \mathrm{m}$ sieve, and parasitic $\mathrm{J} 2$ from the $25-\mu \mathrm{m}$ sieve, respectively. To purify parasitic nematode stages, samples were transferred to $50-\mathrm{ml}$ tubes and $10 \mathrm{ml}$ of $25 \% \mathrm{MgSO}_{4} \cdot 7 \mathrm{H}_{2} \mathrm{O}$ was added to the bottom of each tube using a transfer pipet. Tubes were centrifuged as above and parasitic life stages were collected from the interface and rinsed on a $25-\mu \mathrm{m}$ sieve. To ensure purity of parasitic life stages and to remove remaining plant debris, samples were purified further by manually removing contaminants under a Stemi 2000C stereomicroscope (Zeiss, Jena, Germany). All developmental stages were rinsed either in DEPCtreated water before being stored at $-80^{\circ} \mathrm{C}$ for use in quantitative real-time polymerase chain reaction (qRT-PCR) or resuspended in $4 \%$ formaldehyde in phosphate buffered saline for in situ hybridizations (see below).

Nematode RNA purification and cloning of Mc16D10L fulllength cDNA. Total RNA was extracted from frozen tissue of all M. chitwoodi life stages using the PerfectPure RNA Fibrous Tissue kit (5Prime, Gaithersburg, MD) following the manufacturer's instructions. Approximately $500 \mathrm{ng}$ of purified RNA of each life stage was used as template to synthesize cDNA using the Advantage RT-for-PCR kit (Clontech, Mountain View, CA) according to the manufacturer's protocol. Eighty microliters of DEPC-treated water was added to each $20-\mu$ l reverse transcription product and samples were stored at $-80^{\circ} \mathrm{C}$. To clone full-length cDNA of Mc16D10L, primers Mc16D10-F and Mc16D10-R were designed based on previously published $M$. chitwoodi expressed sequence tag (EST) sequence CD418743 (61). Using primers Mc16D10-F and Mc16D10-R and Phusion polymerase (New England Biolabs, Ipswich, MA), Mc16D10L was amplified from $5 \mu \mathrm{l}$ of cDNA of infective J2 in a Mastercycler pro thermal cycler (Eppendorf, Hamburg, Germany) with the following PCR program: $94^{\circ} \mathrm{C}$ for $5 \mathrm{~min} ; 40$ cycles at $94^{\circ} \mathrm{C}$ for $30 \mathrm{~s}, 52^{\circ} \mathrm{C}$ for $45 \mathrm{~s}$ and $72^{\circ} \mathrm{C}$ for $30 \mathrm{~s}$, followed by $72^{\circ} \mathrm{C}$ for $5 \mathrm{~min}$. The PCR product was cloned into pGEM-T Easy (Promega, Madison, WI) and transformed into E. coli DH5-alpha (New England Biolabs). The plasmid was recovered using the GeneJET Plasmid Miniprep kit (Thermo Scientific, Rochester, NY) and sequenced (Elim Biopharm, Hayward, CA) to confirm the identity of the insert. Sequences were aligned using ClustalW and signal peptides were analyzed with SignalP 3.0 software.

In situ hybridization. To determine the spatial and temporal expression patterns of Mc16D10L in M. chitwoodi, in situ hybridizations were conducted for all life stages. After amplifying the Mc16D10L template with primers Mc16D10-F and Mc16D10-R using Phusion polymerase (New England Biolabs), the sense and antisense probes were synthesized with the PCR DIG Probe Synthesis kit (Roche, Indianapolis, IN) following the manufacturer's instructions. Eggs, infective J2, parasitic J2, J3, $\mathrm{J} 4$, and adult females that were fixed previously in $4 \%$ formaldehyde in phosphate buffered saline for 2 days at room temperature were cut at random with a razor blade, dehydrated, and hybridized in 1.5-ml microcentrifuge tubes with sense (for negative control) and antisense probes at $37^{\circ} \mathrm{C}$ for $16 \mathrm{~h}$ (37). After incubation, residues were removed and probes were detected following Hussey et al. (37). Hybridization patterns were viewed and documented with an AxioObserver A1 inverted microscope equipped with differential interference contrast, AxioCam ICc1 digital camera, and ZEN imaging software (Zeiss). All experiments were replicated at least twice and showed similar results.

Generation of transgenic Arabidopsis and potato. A. thaliana ecotype Columbia (Col-0) was used as wild type in infection assays described below and as genetic background for generating transgenic RNAi lines following the floral dip method (17). Using Agrobacterium tumefaciens strain GV3101, the empty binary 
vector pART27 and the silencing construct pART27(16D10i-2), which contained a pHANNIBAL RNAi cassette based on Mil6D10 (31), were transformed into A. thaliana. For each construct, approximately 500 seeds from 24 individual plants were germinated on 1/2 strength Murashige and Skoog (MS) basal salts media (Caisson, North Logan, UT), supplemented with 3\% D-sucrose, kanamycin sulfate at $50 \mu \mathrm{g} / \mathrm{ml}$ and timentin at $0.5 \mathrm{~g} / \mathrm{liter}$, and solidified with $0.6 \%$ Daishin agar at $\mathrm{pH}$ 5.7. Seedlings were maintained at $22^{\circ} \mathrm{C}$ in a growth chamber with a $12 \mathrm{~h}$ photoperiod. Selection-resistant seedlings were confirmed by PCR for presence of the transgene, and for each construct, six seedlings were carefully transferred to individual pots filled with potting mix and cultivated in the greenhouse $\left(16 \mathrm{~h}\right.$ daylight at $22^{\circ} \mathrm{C}$ and $8 \mathrm{~h}$ nighttime at $20^{\circ} \mathrm{C}$ ). $\mathrm{T}_{1}$ seeds were collected from five individual lines and about $50 \mathrm{~T}_{1}$ seeds for each line were plated on selection media to ensure the presence of the transgene. One plant per line was grown in the greenhouse until maturity to collect $T_{2}$ seeds, later plated to confirm transgenic phenotypes by kanamycin resistance and PCR. For all experiments described here, $\mathrm{T}_{3}$ lines were used; these were confirmed by PCR and Southern blots (Supplemental Figure 1). Three transgenic RNAi lines (D1, D2, and D4), one empty vector line (E2), and a wild type control line (Col-0) were used for infection assays.

The same constructs also were introduced into potato 'Désirée'. Internodal stem pieces were co-incubated with Agrobacterium tumefaciens strain GV3101, carrying the empty pART27 or pART27(16D10i-2) binary vector on sterile CIM media (MS basal salts, $0.25 \mathrm{ppm}$ folic acid, $0.05 \mathrm{ppm}$ D-biotin, $2 \mathrm{ppm}$ glycine, $0.5 \mathrm{ppm}$ nicotinic acid, $0.5 \mathrm{ppm}$ pyridoxine $\mathrm{HCl}, 0.4 \mathrm{ppm}$ thiamine $\mathrm{HCl}, 0.01 \%$ myo-inositol, $3 \%$ D-sucrose, 1 ppm 6benzylaminopurine, $2 \mathrm{ppm}$ 1-naphthaleneacetic acid, and $0.6 \%$ Daishin agar at $\mathrm{pH}$ 5.6) for 3 days in the dark at $19^{\circ} \mathrm{C}$ (14). For the empty pART27 lines, 200 internodal stem pieces were used for transformation, and 250 were used for pART27(16D10i-2), respectively. Stem segments were transferred every 2 weeks to sterile 3C5ZR media (MS basal salts, $0.5 \mathrm{ppm}$ nicotinic acid, $0.5 \mathrm{ppm}$ pyridoxine $\mathrm{HCl}, 1 \mathrm{ppm}$ thiamine $\mathrm{HCl}, 0.01 \%$ myoinositol, 3\% D-sucrose, $0.5 \mathrm{ppm}$ indole-3-acetic acid, $3 \mathrm{ppm}$ zeatin ribose, timentin at $0.5 \mathrm{~g} /$ liter, kanamycin sulfate at $70 \mu \mathrm{g} / \mathrm{ml}$, and $0.6 \%$ Daishin agar at $\mathrm{pH} 5.9$ ) and maintained in a growth chamber at $22^{\circ} \mathrm{C}$ with a $12 \mathrm{~h}$ photoperiod (62). Newly formed plantlets that regenerated from callus tissue on 3C5ZR plates were transferred to propagation media (MS basal salts, 3\% D-sucrose, kanamycin sulfate at $50 \mu \mathrm{g} / \mathrm{ml}$, and $0.6 \%$ Daishin agar at $\mathrm{pH}$ 5.7) and maintained under the same growth conditions (55 plantlets for pART27 and 64 plantlets for pART27(16D10i-2)). Regenerated plantlets were analyzed by PCR and northern and Southern blots to ensure presence of the transgene. Three singleinsertion pART27(16D10i-2) lines (D54, D56, and D57), one empty vector line (E29), and a wild type control line (DES) were chosen for infection assays in the greenhouse. BLAST searches between the gene-specific region of pART27(16D10i-2) and Arabidopsis and potato ESTs and genome sequences did not yield any significant hits, suggesting that no in planta off-target silencing effects were to be expected.

Infection assays. For Arabidopsis, Col-0 wild type and transgenic (E2, D1, D2, and D4) seeds were surface-sterilized and germinated in a growth chamber $\left(22^{\circ} \mathrm{C}\right.$ with a $12 \mathrm{~h}$ photoperiod $)$ on $1 / 2$ strength MS media supplemented with $3 \%$ D-sucrose and kanamycin sulfate at $50 \mu \mathrm{g} / \mathrm{ml}$ (for transgenic lines) and solidified with $0.6 \%$ Daishin agar at $\mathrm{pH}$ 5.7. After 9 days, seedlings were transferred to individual 500-ml pots filled with SunShine Mix \#1 potting mix (Sun Gro Horticulture, Agawam, MA) and grown for 10 days under greenhouse conditions before being inoculated with 5,000 M. chitwoodi eggs per pot. For potato, single nodes of wild type 'Désirée' and transgenic (E29, D54, D56, and D57) lines were cut from plants maintained in tissue culture and propagated in a growth chamber $\left(22^{\circ} \mathrm{C}\right.$ with a $12 \mathrm{~h}$ photoperiod) on MS media supplemented with $3 \% \mathrm{D}$-sucrose and kanamycin sulfate at $50 \mu \mathrm{g} / \mathrm{ml}$ (for transgenic lines) and solidified with $0.6 \%$ Daishin agar at $\mathrm{pH} 5.7$ for 1 month. Following the 1-month period, plants were transferred to individual $500-\mathrm{ml}$ pots filled with autoclaved sand, and cultivated under greenhouse conditions for 10 days before being inoculated with 5,000 M. chitwoodi eggs per pot. Sand was used to facilitate cleaning of potato roots at the conclusion of the infection assay. Arabidopsis did not grow well in pure sand, hence the use of potting mix. Both Arabidopsis and potato plants were maintained in the greenhouse for the duration of the experiment, and watered twice per day with 20-10-20 NPK liquid fertilizer. Infection assays were designed as randomized complete block designs with nine replications for each Arabidopsis line and timepoint (35 and 55 days after inoculation [DAI], respectively) and 10 replications for each potato line and timepoint. At $35 \mathrm{DAI}$, the roots were washed free of growth substrate and for potato, the root fresh weight was measured. Potting mix adhering to roots prevented reliable fresh root weight measurements in Arabidopsis and the weights were omitted. All root systems were stained with phloxine B at $0.15 \mathrm{~g} /$ liter for $15 \mathrm{~min}$ to visualize $M$. chitwoodi egg masses as well as facilitate counting under a Stemi 2000C stereomicroscope (Zeiss). At 55 DAI, root systems were washed free of substrate and for potato, root fresh weights were determined as before. For each root system, eggs were extracted as described above and eggs were counted under a stereomicroscope. Eggs were used to extract RNA or hatch infective J2 for qRT-PCR assays as detailed above. All infection assays were conducted twice and showed similar results. Representative results are shown.

Northern blots for transgenic Arabidopsis and potato lines. Total RNA and small RNA were extracted from $0.5 \mathrm{~g}$ of leaf tissue of each line using the mirVana miRNA isolation kit (Ambion, Austin, TX). For each line, total RNA (20 $\mu \mathrm{g}$ for Arabidopsis and $4 \mu \mathrm{g}$ for potato) was denatured in $50 \%$ deionized formamide (Amresco, Solon, $\mathrm{OH}$ ), separated on a $1 \%$ agarose gel in $1 \times$ TBE buffer (0.9 M Tris base, 0.9 M boric acid, and $20 \mathrm{nM}$ EDTA) and transferred by capillary action onto Nytran $\mathrm{N}$ nylon membrane (Sigma, St. Louis, MO) in 10× SSC (1.5 M NaCl, $0.15 \mathrm{M}$ sodium citrate, $\mathrm{pH}$ 7.0). In addition, $1 \mu \mathrm{g}$ of denatured small RNA was separated on a $15 \%$ polyacrylamide gel with $8 \mathrm{M}$ urea in $1 \times$ TBE buffer and transferred onto Nytran $\mathrm{N}$ membrane as described above. For northern blotting, $\left[\alpha-{ }^{32} \mathrm{P}\right]$ dATP probes (MP Biochemicals, Solon, OH) Mi16D10 and U6 were synthesized by PCR using primers 16D10F5, 16D10R5, U6F, and U6R, respectively (Table 1). Probes were labeled radioactively and purified with DECAprime II kit (Ambion) and Illustra NICK columns (GE Healthcare Life Sciences, Pittsburgh, PA). Membranes were UVcrosslinked and hybridized with radioactive probes overnight at $37^{\circ} \mathrm{C}$ in hybridization buffer $(50 \%$ deionized formamide, $3 \times \mathrm{SSC}$, $0.1 \mathrm{mg} / \mathrm{ml}$ salmon sperm DNA, $1 \%$ sodium dodecyl sulfate, $0.05 \mathrm{M}$ phosphate buffer, $0.2 \%$ bovine serum albumin, $0.2 \%$ polyvinylpyrrolidone, and $0.2 \%$ Ficoll) before being washed three times in $2 \times \mathrm{SSC}$ and $0.2 \% \mathrm{SDS}$ for $20 \mathrm{~min}$ at $46^{\circ} \mathrm{C}$ and exposed to $\mathrm{X}$-ray films for 1 to 5 days at $-80^{\circ} \mathrm{C}$. All experiments were conducted twice and showed similar results.

qRT-PCR transcript levels of Mc16D10L. To analyze the transcript levels of $M c 16 D 10 L$ throughout the life cycle of $M$. chitwoodi, qRT-PCR was performed with cDNA from different nematode life stages harvested from greenhouse nematode stock cultures, as well as from eggs and infective J2 originating from plants used in infection assays (see above). Total RNA was extracted and cDNA generated as described above. qRT-PCR was performed in an iQ Real-Time PCR machine (Bio-Rad, Hercules, CA) using the iQ SYBR Green Supermix kit (Bio-Rad). Internal transcribed spacer 2 (ITS2) rRNA (JN241865) was chosen as internal control gene for qRT-PCR after comparing the expression pattern with that of other $M$. chitwoodi housekeeping genes, such as 18S rRNA (AY757835), actin 2 (CB930959), and glyceralde- 
hyde-3-phosphate-dehydrogenase-1 (CB9332930). Primers McITSRTF and McITS-RTR were designed based on the M. chitwoodi ITS2 gene and used for internal control qRT-PCR reactions (Table 1). Mc16D10L was amplified using primers Mc16D10-RTF and Mc16D10-RTR (Table 1). Each sample was run in triplicate using the following program: $94^{\circ} \mathrm{C}$ for $10 \mathrm{~min} ; 45$ cycles at $94^{\circ} \mathrm{C}$ for $30 \mathrm{~s}, 50^{\circ} \mathrm{C}$ for $30 \mathrm{~s}$ and $72^{\circ} \mathrm{C}$ for $30 \mathrm{~s}$, followed by 91 cycles with a temperature increase of $0.5^{\circ} \mathrm{C}$ after each cycle from 50 to $95^{\circ} \mathrm{C}$. The differences in the expression level of Mc16D10L in $M$. chitwoodi were analyzed using the $2^{-\Delta \Delta \mathrm{Ct}}$ method (52) with cycle threshold $(C t)$ values exported from iQ5 Optical System Software (Bio-Rad). All experiments were conducted at least twice and showed similar results. Representative results are shown.

Data analysis. Number of egg masses, number of eggs, fold changes, and $\log _{10}$ fold changes of Mc16D10L expression were analyzed in Microsoft Excel to calculate means and standard errors. Statistically significant differences were estimated using a Student's $t$ test with alpha $=0.05$ in SAS 9.2 (SAS Institute, Cary, NC).

\section{RESULTS}

M. chitwoodi effector gene Mc16D10L is a ortholog of Mi16D10. In order to identify a putative $M$. chitwoodi ortholog of the $M$. incognita effector gene Mi16D10, M. chitwoodi ESTs were searched using BLASTN $(32,61)$. M. chitwoodi EST CD418743 provided the best match and a full-length sequence spanning the complete open reading frame was cloned from infective $\mathrm{J} 2 \mathrm{cDNA}$ using the gene-specific primers Mc16D10-F and Mc16D10-R (Table 1). The coding sequence of this Mil6D10-like M. chitwoodi ortholog, which will be referred to as Mc16D10L henceforth, had a length of $153 \mathrm{bp}$. A pairwise sequence alignment showed that $70 \%$ of the sequences of Mil6D10 and Mc16D10L were identical on the nucleotide level and $63 \%$ on the amino acid level, respectively (Fig. 1). The N-terminal 32 amino acids of Mc16D10L represent a signal peptide, a characteristic of nematode effector gene products, indicating that this putative effector peptide is most likely secreted. Importantly, a region with similarity to the plant CLAVATA3 (CLV3)/ENDOSPERM SURROUNDING REGION (ESR) (CLE) motif (KRXVPXGPNPLHNR) found in Mi16D10 and other Meloidogyne spp. 16D10 orthologs $(31,55)$ also was conserved in Mc16D10L. The nucleotide sequence of Mc16D10L was deposited in GenBank under accession number KF734590.

Mc16D10L expression changes during nematode development. In situ hybridizations showed that Mc16D10L was expressed most strongly in the subventral gland cells of $M$. chitwoodi infective $\mathrm{J} 2$ (Fig. 2). Weaker expression was found in eggs and subventral gland cells of parasitic J2, whereas no gene activity could be detected in late parasitic life stages by in situ hybridizations. To corroborate the in situ data, qRT-PCR was performed with cDNA from all $M$. chitwoodi life stages except adult males (Fig. 3). Using the expression level of Mc16D10L in eggs as reference, Mc16D10L was upregulated 1.87 -fold in infective $\mathrm{J} 2$ on a $\log _{10}$ scale, which represents a 78 -fold upregulation in absolute terms. In parasitic $\mathrm{J} 2$, mixed $\mathrm{J} 3 / \mathrm{J} 4$, and adult females, $M c 16 D 10 L$ was expressed at a lower level than in eggs, with a fold change of $-0.72,-1$, and -1.6 on a $\log _{10}$ scale (5-fold, 10-fold, and 33-fold downregulation in absolute terms), respectively.

Plant-mediated RNAi of Mc16D10L increases $M$. chitwoodi resistance. No overt phenotypical changes were observed in transgenic Arabidopsis compared with wild type controls. At 35 DAI, the average number of egg masses per plant was reduced $(P<0.05)$ by 36 to $45 \%$ in RNAi lines D1, D2, and D4 compared with the Col- 0 wild type control, and by 50 to $57 \%$ compared with the empty vector control, respectively. At 55 DAI, the average number of eggs per plant in Arabidopsis RNAi lines was

TABLE 1. Primers and probes used for cloning, polymerase chain reaction, and northern and Southern blots

\begin{tabular}{|c|c|c|}
\hline Gene & Primer name & Primer sequences $\left(5^{\prime}-3^{\prime}\right)$ \\
\hline Mi16D10 & 16D10F5 & GTTTACTAATTCAATTAAAAATTTAATT \\
\hline (DQ087264) & 16D10R5 & CAATTATTTCCTCCAGGATTTGGCCC \\
\hline U6 & U6F & GCGCAAGGATGACACGCA \\
\hline$(\mathrm{X} 60506)$ & U6R & GGCTGAGTTATTTTTTTCTG \\
\hline ITS2 & McITS-RTF & GGGGTCAAACCCTTTGGCACGTCTGG \\
\hline (JN241865) & McITS-RTR & GCGGGTGATCTCGACTGAGTTCAGG \\
\hline Mc16D10L & Mc16D10-F & GATATTTAAАTTAАATTATATTCTTCTAАA \\
\hline \multirow[t]{3}{*}{ (CD418743) } & Mc16D10-R & GCTTTATTCAATTTATTTTTATTTATT \\
\hline & Mc16D10-RTF & TTATTTTATCTGTTACTTTTGTGGATTCAGC \\
\hline & Mc16D10-RTR & GCGACCATCATTATTATCATTTCCACC \\
\hline \multirow[t]{2}{*}{ 16D10dsRNA } & $35 \mathrm{~S}-\mathrm{F}$ & TTCGCAAGACCCTTCCTCTA \\
\hline & OCS1 & CTTCTTCGTCTTACACATCACTTGTC \\
\hline
\end{tabular}

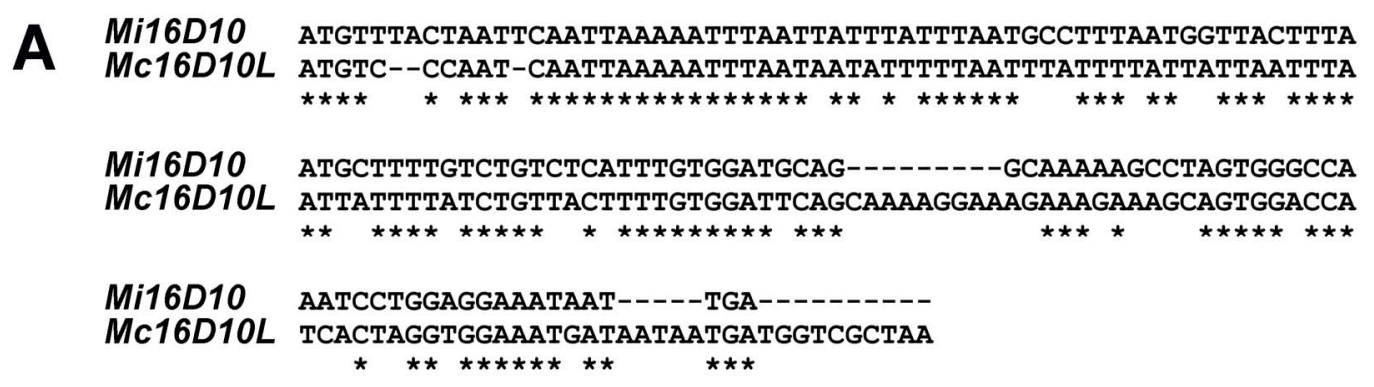

$B \begin{array}{ll}\text { Mi16D10 } & \text { MFTNSIKNLIIYLMPLMVTLMLISVSEVD-A-GKK-PSGPNPGGN-N---- } \\ \text { Mc16D10L } & \text { M-SQSIKNLIIFLIYFIINLIILSVTFVDSAKGKKESSGPSLGGNDNNDGR }\end{array}$

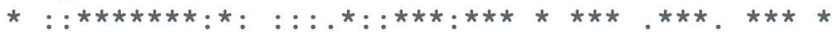

Fig. 1. Sequence alignment of $16 \mathrm{D} 10$ orthologs from Meloidogyne incognita (Mi16D10) and M. chitwoodi (Mc16D10L). A, Nucleotide level. B, Amino acid level. 


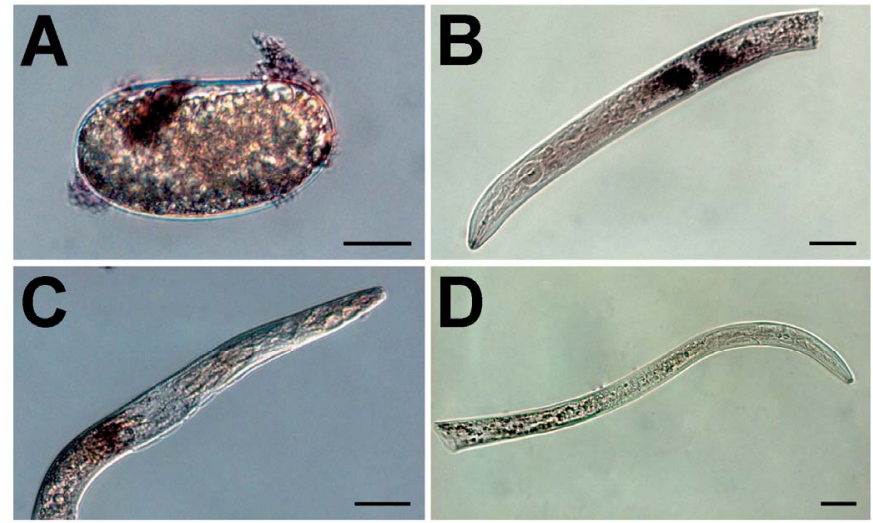

Fig. 2. In situ hybridization of Mc16D10L in different Meloidogyne chitwoodi life stages. Spatial expression pattern of Mc16D10L in A, M. chitwoodi eggs, $\mathbf{B}$, infective second-stage juveniles (J2), and C, parasitic J2. In infective and parasitic J2, Mc16D10L was expressed specifically in the subventral esophageal glands. D, Negative control using a sense probe. Scale bars $=20 \mu \mathrm{m}$.

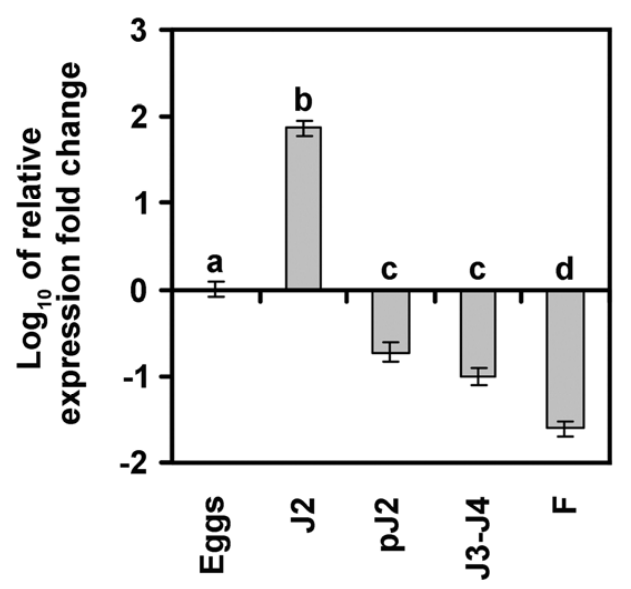

Fig. 3. Relative transcript abundance of Mc16D10L in different Meloidogyne chitwoodi life stages. Using the transcript level of Mc16D10L in eggs as a reference, Mc16D10L was upregulated significantly (1.87-fold on a $\log _{10}$ scale) in infective second-stage juveniles (J2). In parasitic J2 (pJ2), mixed $\mathrm{J} 3 / \mathrm{J} 4$ parasitic juveniles and adult females (F), Mc16D10L was downregulated significantly $\left(-0.72,-1.0-\right.$, and -1.6 -fold on a $\log _{10}$ scale, respectively). Each bar represents the $\log _{10}$ transformed mean of qRT-PCR runs in triplicate with standard errors. Letters indicate statistically significant differences using a Student's $t$ test $(P<0.05)$. reduced by 68 to $74 \%$ compared with the wild type control, and by 59 to $67 \%$ relative to the empty vector control $(P<0.05)$ (Fig. 4). Since expression of dsRNA of Mc16D10L led to enhanced resistance against $M$. chitwoodi in the model plant Arabidopsis, the RNAi construct pART27(16D10i-2) was used to generate stable transgenic potato lines to test whether the same strategy could be applied to engineer $M$. chitwoodi resistance in potato. No overt phenotypical changes were observed in transgenic potato plants compared with wild type controls. At $35 \mathrm{DAI}$, the average number of egg masses per plant was reduced by 63 to $79 \%$ compared with the wild type control, and by 50 to $71 \%$ compared with the empty vector control $(P<0.05)$. Similarly, the average number of eggs per RNAi plant at 55 DAI was reduced by 65 to $74 \%$ compared with the wild type, and by 50 to $63 \%$ compared with the empty vector control lines $(P<0.05)$. Comparable results were obtained when nematode infection was measured as number of egg masses or number of eggs per gram of root fresh weight in potato, with reductions of 44 to $56 \%$ and 53 to $69 \%(P<0.05)$ compared with the empty vector control, respectively (Fig. 5). Northern blots confirmed the expression of small RNAs ranging in size from about 50 to over $150 \mathrm{nt}$ in all transgenic pART27(16D10i-2) Arabidopsis and potato lines when a $16 D 10$ probe was used (Fig. 6).

Potato RNAi lines downregulate Mc16D10L in M. chitwoodi. To investigate the effect of plant-mediated RNAi on the activity of the target gene in nematodes, qRT-PCR was used to analyze the relative transcript level of $M c 16 D 10 L$ in $M$. chitwoodi eggs and J2 harvested from potato plants at 55 DAI. Using the internal ribosomal spacer 2 (ITS2) of nuclear ribosomal DNA as reference (53), it was found that the expression level of Mc16D10L in $M$. chitwoodi eggs that developed on potato plants carrying pART27(16D10i-2) was reduced by an average of 27 to $76 \%$ compared with eggs harvested from wild type control plants $(P<$ $0.05)$. Similarly, the expression level of Mc16D10L in infective J2 that hatched from eggs harvested from potato RNAi lines was reduced $(P<0.05)$ by 52 to $70 \%$ relative to $\mathrm{J} 2$ that developed from eggs collected from wild type control plants (Fig. 7).

\section{DISCUSSION}

Plant-mediated downregulation of the putative effector gene Mc16D10L provides resistance against $M$. chitwoodi in stable transgenic lines of Arabidopsis and potato. The effector gene $16 D 10$ was identified originally in M. incognita but orthologs have since been found in $M$. arenaria, $M$. hapla, and $M$. javanica $(31,33)$. Whereas $16 D 10$ showed 95 to $98 \%$ nucleotide identity
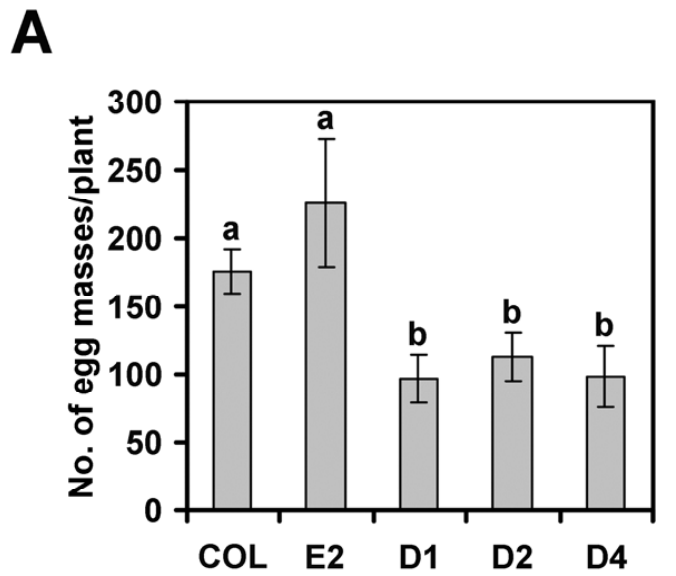

B

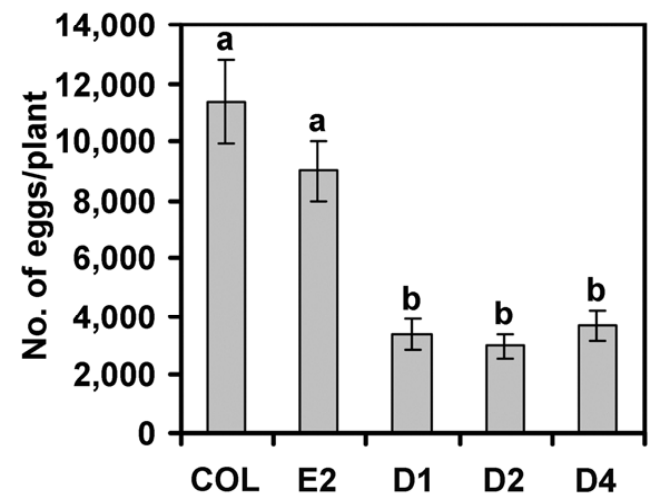

Fig. 4. Reproductive success of Meloidogyne chitwoodi on transgenic Arabidopsis thaliana expressing pART27(16D10i-2). A, Number of egg masses per plant at 35 days after inoculation (DAI), and $\mathbf{B}$, number of eggs per plant at 55 DAI in Columbia-0 wild type (COL), transgenic empty pART27 vector control (E2), and transgenic pART27(16D10i-2) (D1, D2, and D4) plants. Each bar represents the mean of nine plants per independent line and timepoint with standard errors. Letters indicate statistically significant differences using a Student's $t$ test $(P<0.05)$. 
and $100 \%$ amino acid identity between $M$. arenaria, $M$. hapla, $M$. incognita, and $M$. javanica (31), the $M$. chitwoodi ortholog cloned here was less conserved, with $70 \%$ nucleotide and $63 \%$ amino acid identity compared with $M$. incognita. This finding is in line with the more distant phylogenetic position of $M$. chitwoodi relative to other Meloidogyne spp. in which $16 \mathrm{D} 10$ orthologs have been found $(30,69)$. In situ hybridizations and qRT-PCR indicated that $M c 16 D 10 L$ transcription was strongly upregulated in $M$. chitwoodi infective J2. Even though Huang et al. (33) failed to detect transcripts of Mi16D10 in M. incognita infective $\mathrm{J} 2$ by in situ hybridizations, Huang and co-authors later reported that Mi16D10 antiserum confirmed the presence of the Mi16D10 peptide in the subventral glands of $M$. incognita J2 (32). This finding suggests that Mil6D10 is in fact actively transcribed in $M$. incognita infective $\mathrm{J} 2$ and possibly escaped detection by Huang and colleagues' (33) earlier in situ hybridization assays. The function of $16 D 10$ is unknown, but overexpression of the M. incognita ortholog Mi16D10 increased root growth in tobacco hairy roots and in A. thaliana (32). All Meloidogyne 16D10 orthologs, including Mc16D10L, contain a region that is similar to the CLE domain of plant CLE signaling peptides, which could mean that this nematode effector has evolved to modulate root growth and vascular development, processes in which CLE peptides play a key role $(31,55)$.

Stable transgenic Arabidopsis and potato lines overexpressing a 271-nt full-length $16 D 10$ dsRNA construct showed strong resistance against $M$. chitwoodi in this study. No overt changes in plant morphology were observed in the Arabidopsis and potato lines generated in the experiments described here and the level and range of resistance is comparable with what has been reported in other plant-mediated RNAi systems in which cyst or root-knot nematode genes have been targeted $(49,51)$. Controlling $M$. chitwoodi under field conditions is challenging due to its wide host range, development at low temperatures and low damage threshold in potato (21). Standard control tactics heavily rely on the application of fumigant and nonfumigant nematicides, but not all compounds and application methods are equally effective at managing $M$. chitwoodi $(41,42)$. Alternative control methods, such as green manure tend to reduce $M$. chitwoodi, but oftentimes the nematode population remains at economically damaging levels or recovers and quickly reaches previous densities once a susceptible crop is planted $(56,70)$. Most likely, nematodes in deeper soil layers are not affected by synthetic nematicides and green manure applied at the soil surface, and enable a rapid infection of a following potato crop $(41,70)$. It is unknown how transgenic 16D10i-2 potatoes would perform under field conditions, but the systemic nature of the resistance suggests that both roots and tubers would be protected at high levels, even in deeper soil layers. Most likely, an ideal M. chitwoodi management system would include diverse approaches, such as traditional nematicides, good crop rotation strategies, green manure, microbial antagonists, and germplasm that carries endogenous or transgenic resistance genes.

Importantly in this study, qRT-PCR indicated a significant reduction in $M c 16 D 10 L$ transcripts in the second-generation $M$. chitwoodi eggs and infective $\mathrm{J} 2$ that developed on the transgenic
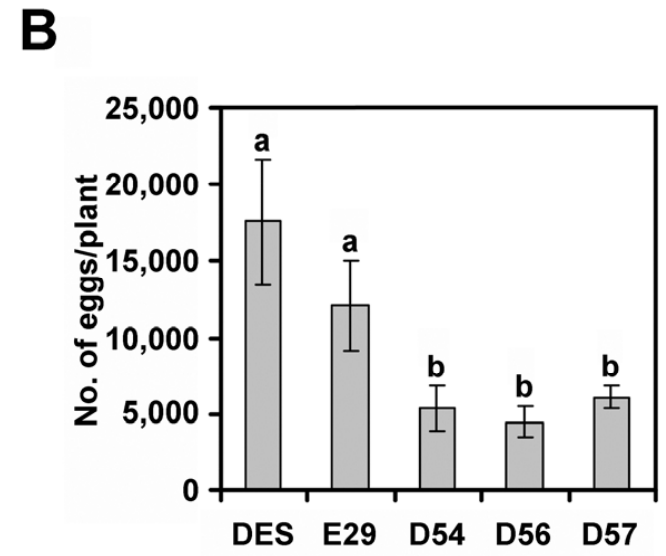

D

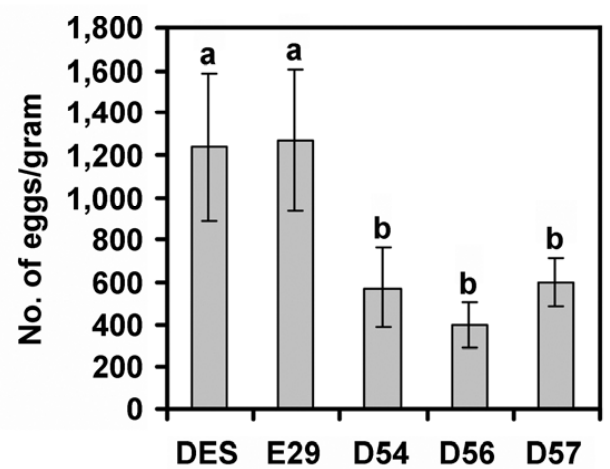

Fig. 5. Reproductive success of Meloidogyne chitwoodi on transgenic potato expressing pART27(16D10i-2). A, Number of egg masses per plant at 35 days after inoculation (DAI), B, number of eggs per plant at 55 DAI, C, number of egg masses per gram of root fresh weight at 35 DAI, and D, number of eggs per gram of root fresh weight at 55 DAI in 'Désirée' wild type (DES), transgenic empty pART27 vector control (E29), and transgenic pART27(16D10i-2) (D54, D56, and D57) plants. Each bar represents the mean of 10 plants per independent line and timepoint with standard errors. Letters indicate statistically significant differences using a Student's $t$ test $(P<0.05)$. 
16D10i-2 potato lines. A recent report suggests that the RNAi effect of $M c 16 D 10 L$ in the nematode is systemic and proliferates upon the initial uptake of plant-derived dsRNAs or siRNAs from the esophagus through the entire body of the female, including the gonads and developing eggs, thereby transmitting the RNAi effect to the offspring (20). RNAi is known to be inheritable in

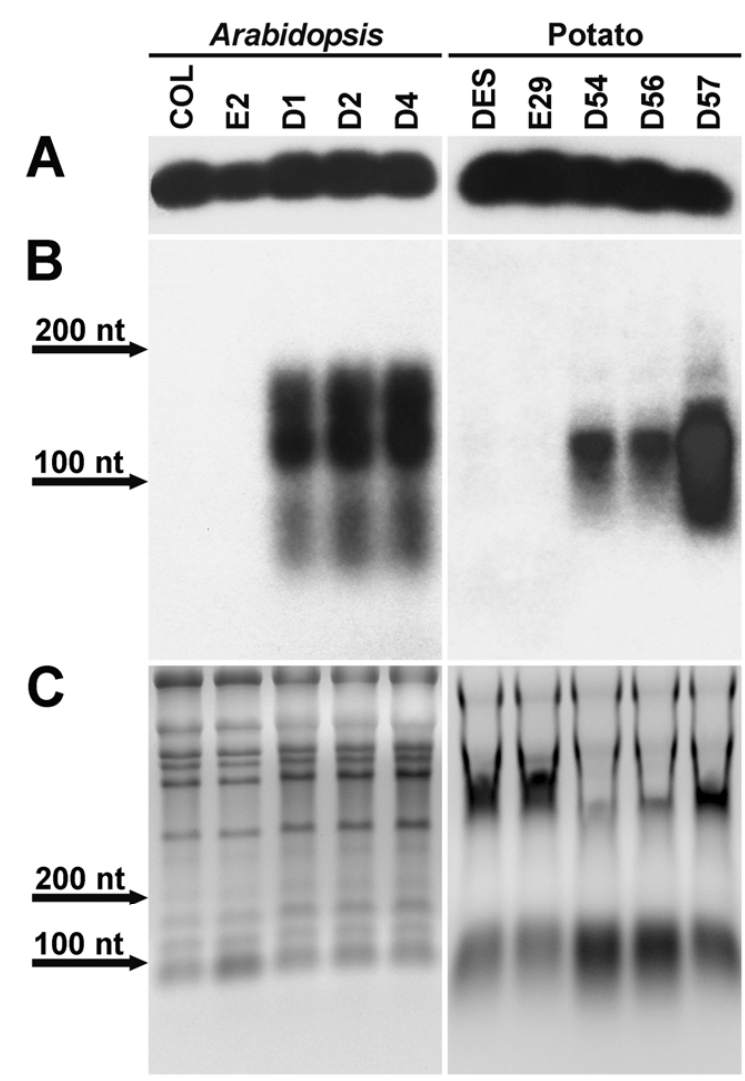

Fig. 6. Production of small RNAs in transgenic Arabidopsis and potato plants. A, U6 small nuclear RNA (snRNA) loading control, B, small RNA, and C, total RNA in Arabidopsis Columbia-0 wild type (COL), transgenic empty pART27 vector control (E2), and transgenic pART27(16D10i-2) (D1, D2, and D4), and in potato 'Désirée' wild type (DES), transgenic empty pART27 vector control (E29), and transgenic pART27(16D10i-2) (D54, D56, and D57) plants.
Caenorhabditis elegans, making it feasible that the underlying genetic mechanisms are conserved in other nematode taxa (26). In spite of repeated attempts it was not possible to verify the production of 16D10-specific siRNAs in the Arabidopsis and potato lines created here, a problem that has been encountered previously for other genes, and most likely due to the limited sensitivity of northern blot assays $(16,74)$. Meloidogyne spp. generate a feeding tube during each feeding cycle and it may act as a filter to prevent clogging of the nematode's mouth spear (38). Earlier studies have shown that root-knot nematodes are able to ingest molecules of 28 to $140 \mathrm{kDa}$, including the green fluorescent protein and crystal proteins formed by the biocontrol agent Bacillus thuringiensis $(50,67,73)$. It is unknown if $M$. chitwoodi took up plant-derived dsRNAs and processed them into siRNAs or whether the nematode directly ingested plant-produced siRNAs in this study. Given that Meloidogyne spp. are able to ingest relatively large molecules, either possibility is conceivable. Previous experiments have demonstrated that a match of $21 \mathrm{nt}$ or less between siRNAs and a target sequence is sufficient to trigger RNAi in animals and that several mismatched base pairs do not interfere with the silencing process $(39,43,57)$. There are numerous conserved regions between Mil6DlO (upon which pART27(16D10i-2) was designed) and Mc16D10L that fall within this size range and could thereby trigger RNAi in $M$. chitwoodi.

Almost all commercial potato cultivars are autotetraploid $(2 n=$ $4 x=48$ ), which makes classic breeding schemes complicated and time-consuming, especially if the high level of heterozygosity related to tetrasomic inheritance is taken into consideration (4). Introgressing traits from wild Solanum spp., e.g., nematode resistance genes, compound already challenging breeding strategies and have to overcome additional complications, such as pre- and postzygotic incompatibility barriers (29). Root-knot nematode resistance in wild Solanum spp. is relatively poorly characterized and a largely untapped resource (59). Given the challenges associated with classic potato breeding, transgenic strategies as described here could present an attractive alternative to breed root-knot nematode-resistant potatoes. One of the advantages of creating transgenic plants with an RNAi-based resistance against nematodes is that in principle no foreign protein is expressed in planta, thereby making the end product potentially more desirable than transgenic crops that express nematicidal peptides or proteins, such as cystatins or neurotransmitter antagonists $(3,22)$. Ideal candidate genes for RNAi-based approaches are specific and only present in the target organisms, even though it has been
A

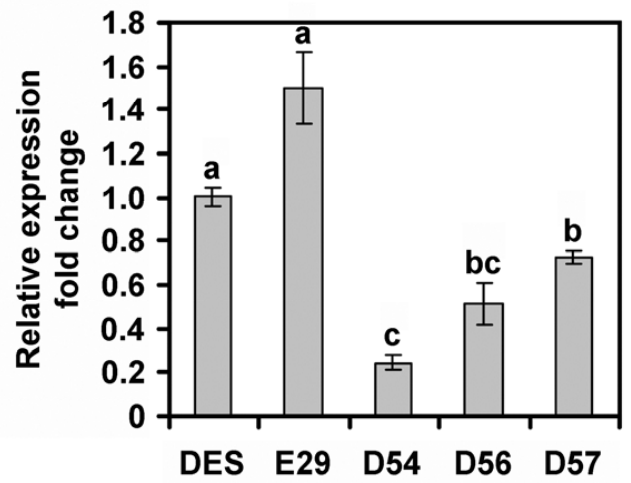

B

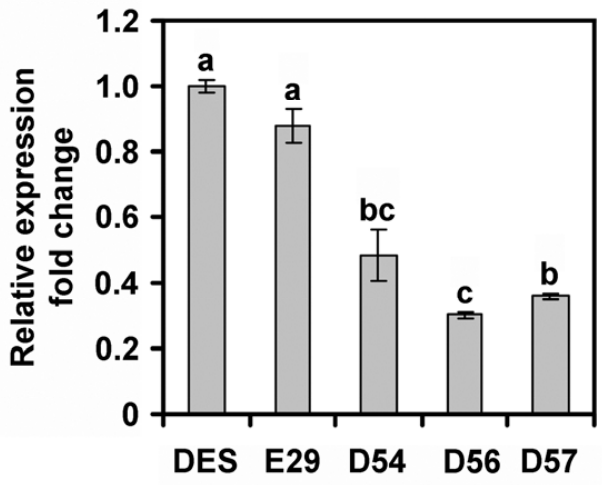

Fig. 7. Relative fold change of $M c 16 D 10 L$ transcript level in second-generation Meloidogyne chitwoodi from transgenic potato lines. A, Relative transcript abundance of Mc16D10L in M. chitwoodi eggs. B, Relative transcript abundance of Mc16D10L in M. chitwoodi infective second-stage juveniles (J2). Eggs were harvested from transgenic potato lines expressing the silencing construct pART27(16D10i-2) and used either directly for qRT-PCR or allowed to hatch infective J2 in modified Baermann pans. Potato lines included 'Désirée' wild type (DES), transgenic empty pART27 vector control (E29), and transgenic pART27(16D10i-2) (D54, D56, and D57). Each bar represents the mean of qRT-PCR runs in triplicate with standard errors. Letters indicate statistically significant differences using a Student's $t$ test $(P<0.05)$. 
reported that silencing of host genes can also result in decreased susceptibility against cyst and root-knot nematodes in Arabidopsis (68). Meloidogyne effectors usually lack homology to genes in other taxa, which makes them a worthwhile group of target genes for safe and specific root-knot nematode control (18). Furthermore, RNAi constructs against more than one effector gene can be stacked to achieve additive effects and aid in creating a more durable nematode resistance (16). In summary, the experiments described here demonstrate that specific silencing of the putative effector gene Mc16D10L leads to M. chitwoodi resistance not only in Arabidopsis but also in stable transgenic lines of potato, thereby opening the door to improved molecular breeding strategies for nematode resistance in this extremely important food crop.

\section{ACKNOWLEDGMENTS}

We thank R. Hussey and E. Davis for the gift of pART27(16D10i-2) and CSIRO, Australia for providing the vectors pHANNIBAL and pART27. We thank J. Cardenas for excellent technical assistance. This work was funded by grants from the USDA, Washington State Department of Agriculture, Washington State Potato Commission, Idaho Potato Commission, and Washington Grain Commission to A. A. Elling. PPNS No. 0638, Department of Plant Pathology, College of Agricultural, Human, and Natural Resource Sciences, Agricultural Research Center, Hatch Project No. WNP00744, Washington State University, Pullman, WA 99164-6430.

\section{LITERATURE CITED}

1. Anonymous. 2009. Meloidogyne chitwoodi and Meloidogyne fallax. EPPO Bull. 39:5-17.

2. Anonymous. 2011. Potatoes 2010 summary. United States Department of Agriculture/National Agricultural Statistics Service.

3. Atkinson, H. J., Lilley, C. J., and Urwin, P. E. 2012. Strategies for transgenic nematode control in developed and developing world crops. Curr. Opin. Biotechnol. 23:251-256.

4. Barrell, P. J., Meiyalaghan, S., Jacobs, J. M. E., and Conner, A. J. 2013. Applications of biotechnology and genomics in potato improvement. Plant Biotechnol. J. 11:907-920.

5. Boydston, R. A., Mojtahedi, H., Brown, C. R., Anderson, T., and Riga, E. 2007. Hairy nightshade undermines resistance of potato breeding lines to Columbia root-knot nematode. Am. J. Potato Res. 84:245-251.

6. Brodie, B. B., Evans, K., and Franco, J. 1993. Nematode parasites of potatoes. Pages 87-132 in: Plant Parasitic Nematodes in Temperate Agriculture. K. Evans, D. L. Trudgill, and J. M. Webster, eds. CAB International, Wallingford, UK.

7. Brown, C. R., Mojtahedi, H., and Bamberg, J. 2004. Evaluation of Solanum fendleri as a source of resistance to Meloidogyne chitwoodi. Am. J. Potato Res. 81:415-419.

8. Brown, C. R., Mojtahedi, H., James, S., Novy, R. G., and Love, S. 2006. Development and evaluation of potato breeding lines with introgressed resistance to Columbia root-knot nematode (Meloidogyne chitwoodi). Am. J. Potato Res. 83:1-8.

9. Brown, C. R., Mojtahedi, H., and Santo, G. S. 1989. Comparison of reproductive efficiency of Meloidogyne chitwoodi on Solanum bulbocastanum in soil and in vitro tests. Plant Dis. 73:957-959.

10. Brown, C. R., Mojtahedi, H., and Santo, G. S. 1991. Resistance to Columbia root-knot nematode in Solanum spp. and in hybrids of $S$. hougasii with tetraploid cultivated potato. Am. Potato J. 68:445-452.

11. Brown, C. R., Mojtahedi, H., and Santo, G. S. 1995. Introgression of resistance to Columbia and northern root-knot nematodes from Solanum bulbocastanum into cultivated potato. Euphytica 83:71-78.

12. Brown, C. R., Mojtahedi, H., and Santo, G. S. 1999. Genetic analysis of resistance to Meloidogyne chitwoodi introgressed from Solanum hougasii into cultivated potato. J. Nematol. 31:264-271.

13. Brown, C. R., Mojtahedi, H., Zhang, L. H., and Riga, E. 2009. Independent resistant reactions expressed in root and tuber of potato breeding lines with introgressed resistance to Meloidogyne chitwoodi. Phytopathology 99:1085-1089.

14. Brown, C. R., Yang, C. P., Kwiatkowski, S., and Adiwilaga, K. D. 1991. Insert copy number, chromosome-number, pollen stainability, and crossability of Agrobacterium-transformed diploid potato. Am. Potato J. 68:317-330.

15. Brown, C. R., Zhang, L., and Mojtahedi, H. 2014. Tracking the $R_{M c l}$ gene for resistance to race 1 of Columbia root-knot nematode (Meloidogyne chitwoodi) in three Mexican wild potato species with different ploidies. Am. J. Potato Res. 91:180-185.

16. Charlton, W. L., Harel, H. Y. M., Bakhetia, M., Hibbard, J. K., Atkinson, H. J., and McPherson, M. J. 2010. Additive effects of plant expressed double-stranded RNAs on root-knot nematode development. Int. J. Parasitol. 40:855-864.

17. Clough, S. J., and Bent, A. F. 1998. Floral dip: A simplified method for Agrobacterium-mediated transformation of Arabidopsis thaliana. Plant $\mathrm{J}$. 16:735-743.

18. Danchin, E. G. J., Arguel, M. J., Campan-Fournier, A., Perfus-Barbeoch, L., Magliano, M., Rosso, M. N., Da Rocha, M., Da Silva, C., Nottet, N., Labadie, K., Guy, J., Artiguenave, F., and Abad, P. 2013. Identification of novel target genes for safer and more specific control of root-knot nematodes from a pan-genome mining. PLoS Pathog. 9(10):e1003745.

19. Dinh, P. T. Y., Knoblauch, M., and Elling, A. A. 2014. Nondestructive imaging of plant-parasitic nematode development and host response to nematode pathogenesis. Phytopathology 104:497-506.

20. Dinh, P. T. Y., Zhang, L., Brown, C. R., and Elling, A. A. 2014. Plantmediated RNA interference of effector gene Mc16D10L confers resistance against Meloidogyne chitwoodi in diverse genetic backgrounds of potato and reduces pathogenicity of nematode offspring. Nematology 16:669-682.

21. Elling, A. A. 2013. Major emerging problems with minor Meloidogyne species. Phytopathology 103:1092-1102.

22. Elling, A. A., and Jones, J. T. 2014. Functional characterization of nematode effectors in plants. Methods Mol. Biol. 1127:113-124.

23. Fairbairn, D. J., Cavallaro, A. S., Bernard, M., Mahalinga-Iyer, J., Graham, M. W., and Botella, J. R. 2007. Host-derived RNAi: An effective strategy to silence genes in plant parasitic nematodes. Planta 226:15251533.

24. Finley, A. M. 1981. Histopathology of Meloidogyne chitwoodi (Golden et al.) on Russet Burbank potato. J. Nematol. 13:486-491.

25. Gavrilenko, T., Antonova, O., Shuvalova, A., Krylova, E., Alpatyeva, N., Spooner, D. M., and Novikova, L. 2013. Genetic diversity and origin of cultivated potatoes based on plastid microsatellite polymorphism. Genet. Resour. Crop Evol. 60:1997-2015.

26. Grishok, A., Tabara, H., and Mello, C. C. 2000. Genetic requirements for inheritance of RNAi in C. elegans. Science 287:2494-2497.

27. Hawkes, J. G. 1990. The Potato: Evolution, Biodiversity and Genetic Resource. Belhaven Press, London, UK.

28. Hawkes, J. G. 1994. Origins of cultivated potatoes and species relationships. Pages 3-43 in: Potato Genetics. J. E. Bradshaw and G. R. Mackay, eds. CAB International, Wallingford, UK.

29. Hermsen, J. G. T. 1994. Introgression of genes from wild species, including molecular and cellular approaches. Pages 515-538 in: Potato Genetics. J. E. Bradshaw and G. R. Mackay, eds. CAB International, Wallingford, UK.

30. Holterman, M., Karssen, G., van den Elsen, S., van Megen, H., Bakker, J., and Helder, H. 2009. Small subunit rDNA-based phylogeny of the Tylenchida sheds light on relationships among some high-impact plantparasitic nematodes and the evolution of plant feeding. Phytopathology 99:227-235.

31. Huang, G., Allen, R., Davis, E. L., Baum T. J., and Hussey, R. S. 2006. Engineering broad root-knot resistance in transgenic plants by RNAi silencing of a conserved and essential root-knot nematode parasitism gene. Proc. Natl. Acad. Sci. U.S.A. 103:14302-14306.

32. Huang, G., Dong, R., Allen, R., Davis, E. L., Baum, T. J., and Hussey, R. S. 2006. A root-knot nematode secretory peptide functions as a ligand for a plant transcription factor. Mol. Plant-Microbe Interact. 19:463-470.

33. Huang, G., Gao, B., Maier, T., Allen, R., Davis, E. L., Baum, T. J., and Hussey, R. S. 2003. A profile of putative parasitism genes expressed in the esophageal gland cells of the root-knot nematode Meloidogyne incognita. Mol. Plant-Microbe Interact. 16:376-381.

34. Humphreys-Pereira, D. A., and Elling, A. A. 2013. Intraspecific variability and genetic structure in Meloidogyne chitwoodi from the USA. Nematology 15:315-327.

35. Humphreys-Pereira, D. A., and Elling, A. A. 2014. Morphological variability in second-stage juveniles and males of Meloidogyne chitwoodi. Nematology 16:149-162.

36. Hussey, R. S., and Barker, K. R. 1973. A comparison of methods of collecting inocula of Meloidogyne spp., including a new technique. Plant Dis. Rep. 57:1025-1028.

37. Hussey, R. S., Huang, G., and Allen, R. 2011. Microaspiration of esophageal gland cells and cDNA library construction for identifying parasitism genes of plant-parasitic nematodes. Methods Mol. Biol. 712:89-107.

38. Hussey, R. S., and Mims, C. W. 1991. Ultrastructure of feeding tubes formed in giant-cells induced in plants by the root-knot nematode Meloidogyne incognita. Protoplasma 162:99-107.

39. Hutvágner, G., McLachlan, J., Pasquinelli, A. E., Bálint, E., Tuschl, T., 
and Zamore, P. D. 2001. A cellular function for the RNA-interference enzyme Dicer in the maturation of the let-7 small temporal RNA. Science 293:834-838.

40. Ibrahim, H. M. M., Alkharouf, N. W., Meyer, S. L. F., Aly, M. A. M., ElDin, A. E. K. Y. G., Hussein, E. H. A., and Matthews, B. F. 2011. Posttranscriptional gene silencing of root-knot nematode in transformed soybean roots. Exp. Parasitol. 127:90-99.

41. Ingham, R. E., Hamm, P. B., Baune, M., David, N. L., and Wade, N. M. 2007. Control of Meloidogyne chitwoodi with shank-injected metam sodium and other nematicides. J. Nematol. 39:161-168.

42. Ingham, R. E., Hamm, P. B., Williams, R. E., and Swanson, W. H. 2000. Control of Meloidogyne chitwoodi in potato with fumigant and nonfumigant nematicides. J. Nematol. (Suppl.) 32:556-565.

43. Jackson, A. L., Bartz, S. R., Schelter, J., Kobayashi, S. V., Burchard, J., Mao, M., Li, B., Cavet, G., and Linsley, P. S. 2003. Expression profiling reveals off-target gene regulation by RNAi. Nat. Biotechnol. 21:635-637.

44. Janssen, G. J. W., von Norel, A., Janssen, R., and Hoogendorn, J. 1997. Dominant and additive resistance to the root-knot nematodes Meloidogyne chitwoodi and M. fallax in Central American Solanum species. Theor. Appl. Genet. 94:692-700.

45. Janssen, G. J. W., von Norel, A., Verkerk-Bakker, B., and Janssen, R. 1995. Detecting resistance to the root-knot nematodes Meloidogyne hapla and $M$. chitwoodi in potato and wild Solanum spp. Potato Res. 38:353-362.

46. Janssen, G. J. W., von Norel, A., Verkerk-Bakker, B., and Janssen, R. 1996. Resistance to Meloidogyne chitwoodi, M. fallax, and M. hapla in wild tuber-bearing Solanum spp. Euphytica 92:287-294.

47. Janssen, G. J. W., von Norel, A., Verkerk-Bakker, B., Janssen, R., and Hoogendorn, J. 1997. Introgression of resistance to root-knot nematode from wild Central American Solanum species into $S$. tuberosum ssp. tuberosum. Theor. Appl. Genet. 95:490-496.

48. Janssen, G. J. W., von Norel, A., Verkerk-Bakker, B., Janssen, R., and Hoogendoorn, J. 1997. Intra- and interspecific variation of root-knot nematodes, Meloidogyne spp., with regard to resistance in wild tuberbearing Solanum species. Fund. Appl. Nematol. 20:449-457.

49. Li, J., Todd, T. C., Lee, J., and Trick, H. N. 2011. Biotechnological application of functional genomics towards plant-parasitic nematode control. Plant Biotechnol. J. 9:936-944.

50. Li, X. Q., Wei, J. Z., Tan, A., and Aroian, R. V. 2007. Resistance to rootknot nematode in tomato roots expressing a nematicidal Bacillus thuringiensis crystal protein. Plant Biotechnol. J. 5:455-464.

51. Lilley, C. J., Davies, L. J., and Urwin, P. E. 2012. RNA interference in plant parasitic nematodes: A summary of the current status. Parasitology 139:630-640.

52. Livak, K. J., and Schmittgen, T. D. 2001. Analysis of relative gene expression data using real-time quantitative PCR and the $2^{-\Delta \Delta \mathrm{Ct}}$ method. Methods 25:402-408.

53. McClure, M. A., Nischwitz, C., Skantar, A., Schmitt, M. E., and Subbotin, S. A. 2012. Root-knot nematodes in golf course greens of the western United States. Plant Dis. 96:635-647.

54. Mitchum, M. G., Hussey, R. S., Baum, T. J., Wang, X., Elling, A. A., Wubben, M., and Davis, E. L. 2013. Nematode effector proteins: An emerging paradigm of parasitism. New Phytol. 199:879-894.

55. Mitchum, M. G., Wang, X., and Davis, E. L. 2008. Diverse and conserved roles of CLE peptides. Curr. Opin. Plant Biol. 11:75-81.

56. Mojtahedi, H., Santo, G. S., and Ingham, R. E. 1993. Suppression of Meloidogyne chitwoodi with sudangrass cultivars as green manure. J. Nematol. 25:303-311.

57. Parrish, S., Fleenor, J., Xu, S., Mello, C., and Fire, A. 2000. Functional anatomy of a dsRNA trigger: Differential requirement for the two trigger strands in RNA interference. Mol. Cell 6:1077-1087.

58. Perry, R. N., Moens, M., and Starr, J. L. (eds.) 2009. Root-Knot Nematodes. CAB International, Wallingford, UK.

59. Phillips, M. 1994. Inheritance of resistance to nematodes. Pages 319-337 in: Potato Genetics. J. E. Bradshaw and G. R. Mackay, eds. CAB International, Wallingford, UK.

60. Porter, I., Banks, J., Mattner, S., and Fraser, P. 2009. Global phaseout of methyl bromide under the Montreal Protocol: Implications for bioprotection, biosecurity and the ozone layer. Pages 293-309 in: Recent Developments in Management of Plant Diseases. Plant Pathology in the 21st Century. U. Gisi, I. Chetand, and M. L. Gullino, eds. SpringerVerlag, Berlin, Germany.

61. Roze, E., Hanse, B., Mitreva, M., Vanholme, B., Bakker, J., and Smant, G. 2008. Mining the secretome of the root-knot nematode Meloidogyne chitwoodi for candidate parasitism genes. Mol. Plant Pathol. 9:1-10.

62. Sheerman, S., and Bevan, M. W. 1988. A rapid transformation method for Solanum tuberosum using binary Agrobacterium tumefaciens vectors. Plant Cell Rep. 7:13-16.

63. Sindhu, A. S., Maier, T. R., Mitchum, M. G., Hussey, R. S., Davis, E. L., and Baum, T. J. 2009. Effective and specific in planta RNAi in cyst nematodes: Expression interference of four parasitism genes reduces parasitic success. J. Exp. Bot. 60:315-324.

64. Spooner, D. M. 2009. DNA barcoding will frequently fail in complicated groups: An example in wild potatoes. Am. J. Bot. 96:1177-1189.

65. Spooner, D. M., and Hijmans, R. J. 2001. Potato systematics and germplasm collecting, 1989-2000. Am. J. Potato Res. 78:237-268.

66. Steeves, R. M., Todd, T. C., Essig, J. S., and Trick, H. N. 2006. Transgenic soybeans expressing siRNAs specific to a major sperm protein gene suppress Heterodera glycines reproduction. Funct. Plant Biol. 33:991-999.

67. Urwin, P. E., Møller, S. G., Lilley, C. J., McPherson, M. J., and Atkinson, H. 1997. Continual green-fluorescent protein monitoring of cauliflower mosaic virus $35 \mathrm{~S}$ promoter activity in nematode-induced feeding cells in Arabidopsis thaliana. Mol. Plant-Microbe Interact. 10:394-400.

68. Van de Cappelle, E., Plovie, E., Kyndt, T., Grunewald, W., Cannoot, B., and Gheysen, G. 2008. AtCDKA;1 silencing Arabidopsis thaliana reduces reproduction of sedentary plant-parasitic nematodes. Plant Biotechnol. J. 6:749-757.

69. van Megen, H., van den Elsen, S., Holterman, M., Karssen, G., Mooyman, P., Bongers, T., Holovachov, O., Bakker, J., and Helder, J. 2009. A phylogenetic tree of nematodes based on about 1200 full-length small subunit ribosomal DNA sequences. Nematology 11:927-950.

70. Wesemael, W. M. L., and Moens, M. 2008. Vertical distribution of the plant-parasitic nematode, Meloidogyne chitwoodi, under field crops. Eur. J. Plant Pathol. 120:249-257.

71. Xue, B., Hamamouch, N., Li, C., Huang, G., Hussey, R. S., Baum, T. J., and Davis, E. L. 2013. The 8D05 parasitism gene of Meloidogyne incognita is required for successful infection of host roots. Phytopathology 103:175-181.

72. Yadav, B. C., Veluthambi, K., and Subramaniam, K. 2006. Host-generated double stranded RNA induces RNAi in plant-parasitic nematodes and protects the host from infection. Mol. Biochem. Parasitol. 148:219-222.

73. Zhang, F., Peng, D., Ye, X., Yu, Z., Hu, Z., Ruan, L., and Sun, M. 2012. In vitro uptake of $140 \mathrm{kDa}$ Bacillus thuringiensis nematicidal crystal proteins by the second stage juvenile of Meloidogyne hapla. PLoS ONE 7(6): 38534

74. Zilberman, D., Cao, X., and Jacobsen, S. E. 2003. ARGONAUTE4 control of locus-specific siRNA accumulation and DNA histone methylation. Science 299:716-719. 